\title{
Un ensayista en los trópicos (sobre Silviano Santiago)*
}

\author{
Mary Luz Estupiñán y raúl rodríguez freire \\ Pontificia Universidad Católica de Valparaíso - Chile
}

\begin{abstract}
Resumen
El presente texto consiste en un acercamiento a la ensayística de Silviano Santiago. Para ello, realizaremos, en primer lugar, un recorrido por su trabajo, partiendo desde su ensayo manifiesto, "El entre-lugar del discurso latinoamericano", hasta llegar a sus ensayos más recientes sobre el cosmopolistismo y la política homosexual. Luego nos detendremos en la llamada polémica Schwarz-Santiago, dado que esta permite resaltar la especificidad de su pensamiento, lo que en conjunto nos ayudará a comprender mejor la apuesta por la diferencia en el ensayismo de Silviano.
\end{abstract}

Palabras clave: Silviano Santiago; ensayo; diferencia; América Latina

\begin{abstract}
This text presents a reading of Silviano Santiago's essays. First, we give some critical clues about his main texts, beginning with his manifest essay: "Latin American Literature: The Space In-between", up to coming to his more recent texts on the cosmopolitism and the homosexual politics. Second, we underline some aspects of the debate called Schwarz-Santiago, so that we can give an idea about the specificity of his thought. In this way we can notice what importance is the notion of difference in Silviano's work.
\end{abstract}

Keywords: Silviano Santiago; essay; difference; Latin America
* El presente texto corresponde a una version revisada y ajustada para la presente publicación de "Un ensayista en los trópicos", que hace de presentación a SANTIAGO, Silviano.Una literatura en los trópicos. Ensayos de Silviano Santiago, 2012, p. 13-34. 
1. LÉVI-STRAUSS, Claude.

Tristes trópicos, 1988, p. 57.
El hombre que encuentra dulce su tierra natal es todavía un tierno principiante; aquel que hace de toda tierra su tierra natal es ya fuerte; pero la persona perfecta es aquella para quien el mundo entero es como una tierra extranjera.

Hugo de San Víctor, Didascalicon

1"Mi carrera se resolvió un domingo de otoño de 1934, a las nueve de la mañana, con una llamada telefónica. Era Célestin Bouglé, en ese entonces director de la Escuela Normal Superior... '¿Siempre tiene el deseo de practicar etnografía?' 'Desde luego"” respondió el joven Claude Lévi-Strauss. ${ }^{1}$ El azar -señaló con posterioridad aquel otrora profesor de escuela, que atravesó a los veintiséis años el mundo para enseñar sociología en la naciente Universidad de São Paulo- fue el responsable de su encuentro con los indios que habitaban ese supuestamente triste país del trópico llamado Brasil. Se trataba de un viaje en el espacio, descrito nostálgicamente en Tristes trópicos, un viaje que le llevaría al encuentro de un presente anacrónico que se le aparecía imposibilitado de autenticidad, pues los indígenas con los que se encontró estaban desprovistos de originalidad gracias a su contacto con un futuro cada vez más cercado, un futuro cada vez menos distante, un futuro que aun responde al nombre de Europa.

Alrededor de treinta años más tarde (1962), un joven intelectual brasileño que realizaba su tesis doctoral en Francia, y que, a la sazón, también contaba con veintiséis años, recibió, no una llamada telefónica, sino una carta, enviada por Heitor Martins, donde se le proponía enseñar literatura brasileña y portuguesa en Nuevo México. El joven Silviano aceptó la oferta; y al hacerlo, daba inicio a otro viaje, no tanto en el espacio, como en el tiempo: se le pedía que enseñara un survey, un curso que fuera desde la carta de Pêro Vaz de Caminha (1500) en adelante: "Sin querer, me comencé a interesar por la historia", señaló en una entrevista hace unos años, $\mathrm{y}$ ha sido ese interés el que le ha permitido insertar el pasado en la cómoda pasividad del presente; se trata de un ejercicio inverso al intentado por el etnólogo francés, puesto que, aunque lo sabía imposible, deseaba regresar los hechos del pasado a su tiempo, con tal de encontrar "su riqueza y su frescura": Levi-Strauss deseó haber vivido "en el tiempo de los verdaderos viajes, cuando un espec- 
táculo aún no malgastado, contaminado y maldito se ofrecía en todo su esplendor", 2 de manera que la tristeza fue la emoción con que nombró su vivencia tropical.

Así es como mientras el azar llevó al intelectual europeo del presente al pasado, al intelectual brasileño le hizo realizar el viaje inverso, del pasado al presente. El primero caracterizó su experiencia con la nostalgia, el segundo con la alegría; mientras "uno" se lamentaba de haber llegado tarde al descubrimiento de la pureza originaria, el "otro" se regocijaba, junto a Oswald de Andrade, por haber encontrado en el "pasado colonial... la posible contribución cultural de las razas indígenas y africanas al diálogo con la Modernidad occidental". ${ }^{3}$ En fin... mientras Levi-Strauss y todos los buscadores de verdades originales lamentaban el contacto cultural, visto como la influencia corruptora de la escritura sobre la tabula rasa indígena descubierta por Caminha, Silviano resaltaba el entre-lugar que emerge cuando dos o más pueblos entran en relación, cuando "se dejan enriquecer por nuevas adquisiciones", como señala en "El entre-lugar del discurso latinoamericano". Solo una mirada maniquea ve la degradación de la supuesta pureza de quienes se enfrentan, violenta o pacíficamente, en ese lugar relacional; solo esta mirada ve que una cultura activa devora a otra pasiva. Desde Uma literatura nos trópicos hasta As raízes e o labirinto da América Latina, incluyendo sus cuentos y novelas, Silviano ha deconstruido estos mitos.
2. Ibídem, p. 48-51.

3. Cita levemente modificada. Leemos en el original: "Tratase da forma como Oswald de Andrade e outros recuperam o que injustamente tem sido classificado de passado colonial brasileiro numa visão reducionista do que é na verdade a possível contribuição cultural das raças indígenas e africanas no diálogo com a Modernidade ocidental". SANTIAGO,

Silviano. "Oswald de Andrade. Elogio da tolerância racial", 2006, p. 137.

"Montaigne abre el capítulo XXXI de sus Ensayos -capítulo en el que nos habla de los caníbales del Nuevo Mundo-, con una referencia precisa a la Historia griega”. Así comienza "El entre-lugar del discurso latinoamericano” (1971), aquel ensayo manifiesto, como le han llamado algunos críticos en Brasil. No es el texto con el que Silviano inaugura su escritura, pero es el que abre Uma literatura nos trópicos (1978), su primer libro de recopilación ensayística. Con ello, el autor estableció de una vez la inscripción no en un género, sino en una manera de comprender el mundo, después de todo, eso es el ensayo y el legado de Montaigne. Silviano abre entonces su manifiesto con la misma referencia citada en "Los caníbales", donde su autor rememora a Plutarco, para actualizar las palabras que el Rey Pirro pronunciara frente al ejército romano, que lo aguardaba sin temor al otro lado del río Siris: "No sé qué clase de bárbaros son' [...] 'pero la disposición del ejército que veo en absoluto es bárbara”". Esta estrategia escritural coloca su im- 
4. ADORNO, Th. W. "El ensayo como forma", 2009, p. 11-34. pulso ensayístico en la misma huella que comenzó a trazar el humanista francés, y ambos discutirán el lugar del otro, no en términos de buen salvaje, sino en relación con su aporte a la cultura occidental. Pero Silviano no es Montaigne, ni escribe en su época, ni desde un lugar que valore sin objeciones su discurso: por ello, en "El entre-lugar del discurso latinoamericano", "Hablar, escribir, significa: hablar contra, escribir contra”, pues el lugar periférico desde el que se enuncia, incluso dentro de nuestro continente, es el lugar de lo minoritario: sus ensayos contemplan el diálogo con la lengua de aquellos y aquellas que han sido desconsiderados: el negro, el indio, el homosexual, el migrante. De esta manera, Silviano se une a quienes han hecho del ensayo una práctica política que reinscribe la potencia de lo que la doctrina rechaza: lo cambiante, lo efímero, lo fragmentario, lo indigno de la filosofía dominante; o como diría Adorno, al suspender la idea de identidad, el ensayo logra aprehender lo que se le escapa al pensamiento oficial. ${ }^{4}$ En sus textos, se vuelve atractivo ese desprendimiento de lo establecido, junto a una actitud de extranjería, incluso para con su propia tierra, que permite el ejercicio de la crítica allí donde reina la comodidad del orden y lo conocido. Desde sus primeros ensayos, Silviano comenzó a dislocar la cómoda academia brasileña, cuya historia literaria iniciaba con un tiempo decimonónico del cual parecía no haberse desprendido. El romanticismo era su punto de partida y la colonia, por tanto, no existía... pero tampoco al siglo XX le era fácil ser considerado. De ahí que Uma literatura nos trópicos se haya convertido prácticamente en un dispositivo mediante el cual se puede mirar, "olhos livres", cada uno de sus anacrónicos presentes (Didi-Huberman); un ejercicio, por cierto, que comenzó a realizarse fuera de Brasil, con la experiencia de los conflictos raciales estadounidenses, junto al encuentro de mexicanos, indígenas y puertorriqueños. Para señalarlo con otras palabras, los primeros ensayos de Silviano constituyeron una crítica desencializadora de la literatura y la cultura comparadas, dentro y fuera de Brasil, con lo cual se anticipaba en varios años a un trabajo similar que vendrían a realizar los discursos que se reúnen bajo la rentable etiqueta de Estudios Postcoloniales.

No es ocioso imaginar cuál habría sido el juicio de Goethe, de haber conocido en su juventud la poesía árabe y la literatura china, y de haber percibido que para comprender el presente se necesitaba conocer los siglos transcurridos. De 
manera que fue, ya viejo, cuando emprendió uno de esos viajes inmóviles, primero en el tiempo, y luego en el espacio. Gracias a ello, hoy nos beneficiamos de una de sus mayores aportaciones a la literatura: su idea de Weltliteratur (literatura universal). Estos tardíos viajes le llevaron a realizar, en 1826, una autocrítica bastante dura: "De haber sabido ya por aquel entonces con la misma claridad como ahora la cantidad de cosas notables que nos aguardan allí desde hace siglos y milenios, no habría escrito ni una sola línea, y me habría dedicado a otra cosa”.${ }^{5}$ Es obvio que aquí se está refiriendo al tiempo de los griegos, pero luego, en otro momento señala que "en cinco siglos, los árabes solo reconocieron por buenos a siete poetas, y entre los que rechazaron había muchas insignificancias que eran mejores que yo". Y fue a propósito de un tiempo de intensa y variada lectura, que dio con una novela china "singular en extremo" y superior a todas las otras, cuando formuló abiertamente la "literatura universal”. Uno está tentado a comparar el elogio de Goethe con el que Montaigne dedicara a los versos de una canción perteneciente a los bárbaros. Vale la pena entonces, citar al autor alemán:

[L]a verdad es que los alemanes cuando no somos capaces de ver un poco más allá del estrecho círculo de nuestro entorno, caemos demasiado fácilmente en esa pretensión [se refiere a creerse superiormente dotado para la poesía]. Por eso me gusta echar un vistazo a lo que hacen las naciones extranjeras y recomiendo a cualquiera que haga lo mismo. Hoy en día la literatura nacional ya no quiere decir gran cosa. Ha llegado la época de la literatura universal y cada cual debe poner algo de su parte para que se acelere su advenimiento. ${ }^{6}$

Es sorprendente que la literatura universal haya sido convocada precisamente en un momento de florecientes nacionalismos (a los cuales las literaturas nacionales no dejaron de aportar, sino hasta hace muy poco, y por agotamiento), y en un contexto donde los coterráneos de Goethe no aceptaban nada que no proviniera sino de Atenas o Roma. De todas maneras, es posible comprender que la literatura universal se ampara en el hecho de que "todas las literaturas extranjeras se sitúan en el mismo plano que la propia”, y juntas contribuyen a una meta común. No obstante, para ello "hay que informarse del presente estado de cosas en el mundo”. Según E. R. Curtius, Goethe lanzó un planteamiento equivalente a la necesidad de un punto de confluencia para la multiplicidad de relaciones literarias, relaciones siempre divergentes ${ }^{7}$ que traspasan los límites nacionales. Pensar el tiempo y el espacio obliga a amar el mundo como tierra extranjera... Por supuesto que Goethe siguió estimando por sobre todo a griegos y romanos... pero
5. ECKERMANN, J. P.

Conversaciones con Goethe, 2005, p. 206.

6. Ibídem, p. 267. Énfasis agregado.

7. CURTIUS, E. R. "Goethe como crítico”, 1989, p. 46. 
8. SANTIAGO, Silviano. "A pesar de dependiente, universal", 2012, p. 110.

9. Cf. Ídem. Glossário de Derrida, 1976. lo importante es que nos muestra que aún en tiempos aciagos es posible apreciar la diferencia. Estaba fascinado con el auge de los medios de transporte, pues creía que estos también contribuirían al aceleramiento del tiempo y la literatura universal sería inminente. Pero no muchos fueron los que comprendieron sus visiones y su apuesta por la diversidad se fue perdiendo lentamente, hasta volverse la suma de las literaturas nacionales, cuya diversidad la comparatística no haría sino controlar. De ahí que la universalidad haya tenido que ser pensada una vez más, y de entre quienes lo hicieron, Silviano Santiago es uno de los que con mayor intensidad lo han hecho:

La universalidad es o bien un juego colonizador, que consigue poco a poco la homogenización y la totalización occidental del mundo, a través de la imposición de la historia europea como Historia universal, o bien es un juego diferencial en que las culturas, incluso aquellas que se encuentran en una situación económica inferior, se ejercitan dentro de un espacio mayor, con el fin de acentuar los choques de las acciones de dominación y la reacción de los dominados. ${ }^{8}$

Como el tiempo de Goethe no es el que nos ha tocado vivir, aunque sus ruinas acompañan las nuestras, de todas maneras debemos estarle agradecidos, y comenzar a pensar, como Silviano, sobre el presente. Silviano no es un cronista, sino un apostador. Como Montaigne, siempre actúa como si estuviera sobre un terreno que no le pertenece, siempre más allá. Hace casi cuarenta años que leyó su ensayo-manifiesto, y desde entonces no ha dejado de pensar sobre la diferencia, cultural o vivencial. Aunque ya en "Eça autor de Madame Bovary” (1970) vemos aparecer su programa: buscar en las obras su carácter visible, es decir, su diferencia, desconsiderando las semejanzas con la cultura metropolitana, que deja para el crítico ocioso. De manera que Silviano no se preocupa por las fuentes o las influencias, no busca la reproducción impoluta de un discurso (suponiendo que tal cosa sea posible) ni sus unidades, sino el trabajo que lo suplementa, que lo vuelve otro, como la lectura de la carta de Caminha realizada por Oswald en Pau-Brasil y su reescritura de la historia.

Sus ensayos son el primer intento, serio y acertado, por trabajar con la deconstrucción en Brasil y también en Latinoamérica, sin someterse a ella, ${ }^{9}$ y lo hace de una manera brillante, al entregarnos un conjunto de herramientas que ponen en jaque las ideas metafísicas de la crítica latinoamericana tradicional, y dando además un gran golpe no solo al dominante sistema literario, sino también a la dictadura, a la izquierda autoritaria y al imperialismo estadounidense. Silviano encara el asalto a las metrópolis, al señalar que "la mayor contribu- 
ción de América Latina a la cultura occidental proviene de la destrucción de los conceptos de unidad y pureza" ${ }^{10}$. Con ello disloca la atención desde la aparente pasividad del margen hacia el trabajo "que activa y destructivamente desvía la norma, un movimiento que resignifica los elementos preestablecidos e inmutables que los europeos exportaban al nuevo mundo". ${ }^{11}$ Se trata de rebasar creativa y políticamente los muros de la supuesta identidad/inferioridad latinoamericana, y hacer de la transgresión una de las formas de "nuestra" expresión, una forma que niega la pasividad. Pero no se queda ahí, pues una vez señalado este aporte (1971) y leída en otra clave la idea de dependencia (1982), continúa removiendo el orden de aquella pregunta que insiste en el lugar periférico, inferior, de Brasil -y por extensión de América Latina-, y que vio/ve en el exotismo la forma en que estos lugares han aportado a la producción de la teoría. Así, en el lugar de Carmen Miranda y su "tutti-fruti hat", instala a Clara Nunes y su cascabel; y ante el imperativo norteamericano de los años 70 de salir del closet como política gay, propone la figura del malandro como posibilidad de transgresión, pues esta encontraría eco en algunas prácticas populares brasileñas. ${ }^{12}$ Vamos viendo que la de Silviano es una política de la escritura.
10. Ídem. "El entre-lugar del discurso latinoamericano", 2012, p. 65.

11. Ibídem.

12. Cf. Ibídem, p. 199-211.

13. Ibídem, p. 232.

Pero al develar que lo importante no son las copias ni los originales, sino sus diferencias, también mostró que la historia de Europa nació de la supresión de sus propias diferencias y de la de los demás; un proceso de violencia exportado por el orbe en nombre de la civilización. Silviano comenzó a provincializar Europa mucho antes de que esta idea se impusiera como práctica en el pensamiento postcolonial. Heredero heterodoxo de Montaigne y Goethe, ha mostrado que la literatura no tiene por qué operar en el nivel del signo, y si lo hace, es solo para deconstruir su pasajera estabilidad; develar así la ficción de toda unidad o totalidad cultural, acentuando la radical diferencia de toda otredad y la otredad que implica toda diferencia. Últimamente lo ha hecho mostrando niveles subyacentes como la "redefinición cosmopolita y pobre de la cultura afro-brasileña", ${ }^{13}$ condenada por siglos bajo la tiranía del signo-nación. El largo trabajo de Silviano, preocupado por develar las ilusiones, al luchar a favor de un democrático por-venir, ha dado lugar a una ensayística en los trópicos, desde donde, como Prometeo, anuncia, no el fuego, sino el entre en el que se reunirán los diferentes mundos, individuales y colectivos, en una infinita y mutua diseminación... 
14. Ídem. Stella Manbattan, 1985.

15. Cf. Ibídem, p. 77-95.

16. Ibídem, p. 211.
Si bien su trabajo ensayístico es el lugar que le ha permitido pensar y deshacer ficciones epistemológicas, este también ha tenido cruces con su narrativa, tal como lo vemos en su novela-ensayo Stella Manhattan. ${ }^{14}$ A través de este recurso escritural, Silviano puede suplementar sus críticas a las formas de pensamiento que sostienen una unidad cultural (sea en términos nacionales, de género, sexualidad o de raza), así como reflexionar sobre las salidas epistemológicas que ve a partir del énfasis en la diferencia; ambas maniobras tienen un eco en los escenarios y personajes presentados en su novela. En ella incorpora un ensayo denominado "comienzo: el narrador", donde recurre constantemente a epígrafes que dejan ver los textos, detrás del texto. Esto es posible gracias a la adopción de una escritura fragmentada, a la que suma unos personajes de subjetividad múltiple. En este sentido, también trastocó la estructura narrativa de los años 80 , vehiculizada en "la denuncia social populista". ${ }^{15}$

En "El homosexual astuto", continúa escribiendo contra -y criticando- la cultura gay metropolitana, la cual se ha intentado imponer en América Latina como vía para situar una subjetividad gay, de un lado, y desmontar la homofobia, de otro. Más que abogar por la política del asumirse públicamente como homosexual, Silviano opta por la creación de formas imperceptibles de militancia, como lo devela cuando pregunta: “¿Si la subversión a través del anonimato valiente de las subjetividades en juego, no establece un mejor escenario para el futuro diálogo entre heterosexuales y homosexuales, que el enfrentamiento abierto por parte de un grupo que se automarginaliza?" 16 Como vemos, lejos de fabricar guetos o comunidades aisladas, el trabajo de creación pasa también por el diálogo y no por la "imitación" de patrones e instituciones dominantes para legitimarse en la diferencia. A partir de la figura del malandro plantea un punto de fuga hacia ese nuevo horizonte para la invención de las homosexualidades en América Latina, que no es volver al closet, pero tampoco salir de él, como lo pretendió la política estadounidense de liberación sexual de los 70. Es pensar y vivir desconsiderando el closet y su normativización.

Por otra parte, la deconstrucción de los conceptos de unidad y pureza también permite darle un vuelco al debate radicado en esa falsa dicotomía que todavía tiende a separar el pensamiento entre lo propio y lo ajeno, como si con ello se 
pudiera resolver el problema de la subalternización de la intelectualidad no metropolitana. La izquierda identitaria latinoamericana no solo ha caído, sino que ha profundizado el juego maniqueo de las polaridades, ahora encubiertas en nombre de la decolonialidad. El mismo año que Silviano presentaba su apuesta por la diferencia del discurso latinoamericano y, por extensión, de todo discurso, Roberto Fernández Retamar vociferaba su relectura del arielismo, y ponía en boca de Caliban el grito metafísico de lo "nuestro". Es cierto que Próspero impuso su monolingüismo, pero la forma que adquiere su denuncia reinstala la fuerza dominante, no la aminora. La posibilidad de un pensamiento "latinoamericano" lleva implícitamente el reconocimiento de un pensamiento "europeo", obliterando que la posibilidad de un pensamiento tal se levanta sobre cientos de contactos transculturales, violentos unos, calmos otros, pero siempre a partir de un entre-lugar que hace imposible el determinismo de un origen. Lo que fue Grecia, sabemos hoy, lo fue gracias al influjo afro-asiático: Atenea, la salvadora de Ulises, es la traducción de Neith, la diosa egipcia de la caza y la sabiduría, pero también creadora de dioses. Creer entonces en un pensamiento "propio" es insistir en las nociones eurocéntricas que reinstalan una matriz colonialista que no se cuestiona debidamente el lugar de las jerarquías. Paradójica defensa además, toda vez que se la enuncia desde un discurso disciplinario como la historia o como la literatura, narrativas maestras que, salvo excepciones, no se han destacado por su apertura a la heterogeneidad. O cuando se apela a la idea de nación, esa comunidad imaginada... por europeos. La resistencia a dejar de lado el pensamiento de la propiedad, señaló Eneida Leal Cunha a propósito del trabajo de Silviano y su diferencia respecto de la mirada marxista de un Roberto Schwarz, recae finalmente en divergencias teóricas que se encuentran en la base de cada uno, en otras palabras, en las formas de leer la dependencia. A pesar de que revisa críticamente esta disputa, Schwarz termina afirmando el carácter postizo inevitable de la cultura brasileña, ${ }^{17}$ carácter donde "el vínculo con lo 'Otro', lo popular, pasa [exclusivamente] por lo económico, por el modo de producción", ${ }^{18}$ sin reconocerle ningún lugar, ni siquiera recordando la violencia con que la diferencia fue dramáticamente subalternizada. De manera que la "la incompatibilidad entre las dos interpretaciones de la dependencia cultural expuestas, como el contraste de los sistemas de pensamiento occidental que las forman, está en el lugar en que se concibe la producción de los valores y de los sentidos" ${ }^{19}$ El marxismo que profesa el autor de Um mestre na periferia do capitalismo le hace sobre considerar el plano económico, y afirmar en consecuencia que es la estructura socioeconómica del país la que inscribe a la copia como característica central de su cultura.
17. SCHWARZ, Roberto.

"Nacional por Subtração", 2006, p. $29-48$.

18. SOVIK, Liv. "OO Haiti é aqui

/ O Haiti não é aqui': Música popular, dependência cultural e identidade brasileira na polêmica Schwarz-Silviano Santiago", 2002, p. 283.

19. CUNHA, Eneida Leal. "Leituras da dependência cultural", 1997, p. 126-139. 
20. SCHWARZ, Roberto.

"Cultura y política en el Brasil

(1967-69). Algunos esquemas”. Casa de las Américas, 1970, p. 18. Énfasis agregado. El título en portugués es distinto en lo que respecta a los años, aunque el texto es el mismo: "Cultura e política, 1964-69”, 1992, p. 73.
Ello implica continuar con un juego unidireccional, casi en términos de aculturación, o autoaculturación más bien, cuestión que no solo resta toda agencia, sino que además borra o desconoce el aporte "periférico" a las relaciones culturales más allá de la propia nación y de los simulacros democráticos del mercado, a la vez que asume la mirada elitista respecto de los sectores populares, como demostrara no hace mucho Liv Sovik, al contrastar la mirada sobre el tropicalismo entre Schwarz y Silviano, a partir de ensayos que lo refieren, negativamente el primero, positivamente el segundo. Revisemos una cita del crítico paulista comentada por Liv, con tal de resaltar su desconsideración de la diferencia:

Sistematizando un poco, lo que se repite en estas idas y venidas es la combinación, en momentos de crisis, de lo moderno y de lo antiguo [...] Superficialmente, esta combinación indica apenas la coexistencia de manifestaciones ligadas a diferentes fases del mismo sistema. (En nuestra exposición no interesa la famosa variedad cultural del país, en la que, de hecho, se encuentran presentes religiones africanas, tribus indígenas, trabajadores ocasionalmente vendidos como esclavos, trabajo a medias o subempleo, ni complejos industriales). Lo importante es el carácter sistemático de esta coexistencia, y su sentido, que puede variar. ${ }^{20}$

En su intento por explicar el predominio de una cultura de izquierda durante los primeros años de la dictadura en Brasil, Schwarz apela a la que será su estrategia de lectura predilecta: recurrir, a veces sin señalarlo, a nociones de totalidad, llámesele estructura o sistema. Ello implica obviamente la desconsideración de sus diferencias internas (y externas), como queda claro en esta cita, pues "no [le] interesa la famosa variedad cultural del país”. Mientras para Schwarz el paréntesis es secundario, es justamente lo que él encierra aquello que toma importancia vital en el trabajo de Silviano. Desmerecerlo, por secundario, es mantener incólume la jerarquización instalada a sangre y fuego por los colonizadores portugueses y criollos. La apuesta por la diferencia no desconoce la fuerza de las marcas económicas, pero su potencia radica en una lectura a contrapelo que intenta deconstruir las ideas de superioridad y pureza, con tal de develar cuánto ellas le deben a su otredad. Solo negándola es que las ideas de "Nación" y "Europa" han podido mostrarse como autosuficientes, solo negándola es que han podido existir. Antes de ser recordado como el año del descubrimiento de América, 1492 fue el año en que España y, por extensión, la Europa cristiana, se deshizo de árabes y judíos, fue el año en que comenzó su proceso de centramiento unitario. Se podría señalar, recurriendo a otro texto del mismo Silviano, que el intento de analizar un acontecimiento o incluso un texto 
en términos de unidad (i.e., reconstitución totalitaria), incluso cuando se reconocen sus diferencias y/o sus colaboraciones internas, nos envía a una lectura cerrada, donde funciones, elementos o lugares solo responden a la determinación de su orden. Siendo así, la diferencia efectiva, operacional, no cuenta; ${ }^{21}$ es, por tanto, la necesidad de su reconocimiento la que lleva a suspender los análisis unitarios y centrados -que gracias a la lingüística dominaron buena parte de la crítica, literaria y cultural-, y a buscar "los conceptos hasta entonces no pensados por el estructuralismo", con tal de salir "de los términos que 'solicitaban' (que abalaban la totalidad, etimológicamente) el edificio de la metafísica occidental"22. Ahí es cuando aparecen no solo la diferencia, sino también la transgresión y la contradicción. Por supuesto que esta lectura no consiste, como tantas veces se la ha intentado burdamente leer, en una simple apelación a la diferencia per se, ni a una inversión de jerarquías, que pretenda valorar ahora lo subalternizado, pues el mercado ha terminado haciendo de estas prácticas su mayor rentabilidad contemporánea; ${ }^{23}$ es mostrar la falacia de las dicotomías, develar la ficción monolítica y enrostrar el sesgo elitista de la crítica cultural marxista (y de la crítica de izquierda en general), que desconsidera a la población que no participa de los intercambios logocéntricos. ${ }^{24}$ Silviano lo consigue al salir de la cultura moderna en la que se centran Schwarz y todo el pensamiento identitario, al releer la diferencia desde la colonia en adelante, la misma a la que Machado de Assis le niega su aporte a la "civilização brasileira", al señalar que esta no le debe nada al "elemento indígena" 25 . Es más, esta crítica de Silviano le permite incluso suspender la defensa moderna de un Habermas, al develar su inherente eurocentrismo, cuestión que no le preocupa a sus acólitos latinoamericanos, que lo citan cada vez que quieren deshacerse de Foucault o Derrida, sin tener la necesidad de leerlos. En su lectura de la vanguardia, el pensador alemán tiende a reconocer la decadencia histórica con el signo de "lo bárbaro, lo salvaje y primitivo", ${ }^{26}$ uniéndose así a todos los reduccionistas que no reconocen la "contribución positiva de lo no europeo a la causa de Europa o al sentido de la historia moderna"27. Silviano insiste que el desconocimiento de la diferencia que representan los pueblos no europeos, termina valorizando una razón moderna etnocéntrica que, insistimos aquí, el pensamiento identitario reinscribe localmente. Tal autocolonización acabará cuando logremos articularnos no en función de una identidad nacional, sino a través de una comunidad contingente que reúna -más allá del color de piel, del país, del género, de la etnia- a todos los que hemos sido subalternizados; parafraseando a Ranajit Guha, cuando se articule la heterogeneidad demográfica entre la población subalternizada $\mathrm{y}$ todos aquellos que se comportan como elites. ${ }^{28}$
21. SANTIAGO, Silviano.

"Análise e interpretação", 1978, p. 191-207.

22. Ibídem, p. 199.

23. Hace bastante tiempo, Nelly

Richard alertó de los peligros del boom de la diferencia, y la necesidad de sospechar de la "centralidad de los márgenes". $\mathrm{Al}$ respecto, Cf. "Periferias culturales y descentramiento de los márgenes", 1991, p. 5-7. También en Masculino/ Femenino, Richard apuntaba a que tal boom no permitía el acceso a los mecanismos de intervención y confrontación discursiva e institucionales que permiten constituirse en sujetos y "no en objetos del discurso de la otredad". 1989, p. 80. Cf. también La estratificación de los márgenes, 1989.

24. SANTIAGO, Silviano. "Análise e interpretação", 1978, p. 283.

25. ASSIS, Machado de. "Notícia da atual literatura: Instinto de nacionalidade", 1962, p. 801-809.

26. HABERMAS, Jürgen. "La modernidad, un proyecto incompleto", 1988, p. 19-36.

27. SANTIAGO, Silviano. "Oswald de Andrade. Elogio da tolerância racial”, 2006, p. 142.

28. GUHA, Ranajit. "Sobre algunos aspectos de la historiografía colonial de la India", 2013, p. 82. 
"Nacional por Subtração", 2006, p. 30.

30. DE MAN, Paul. “Crítica y crisis”, 1991, p. 7-25.

31. LÓPEZ, Natalia y RODRÍGUEZ FREIRE, raúl. "Sobre Estudios Culturales, literatura y subalternidad: entrevista a John Beverley". Revista de Crítica Cultural, 2007, p. 66.
Si hemos recogido el debate con Roberto Schwarz, es porque vemos que su postura es compartida por otros críticos que ven con frivolidad el reconocimiento y el trabajo de la alteridad, críticos que también reconocen la ingenuidad que recorre la denuncia del trasplante cultural, pero que son ciegos a la filosofía de la diferencia, pues ven en ella o en su lectura latinoamericana, solo una supuesta actualización, una puesta a la moda que responde a su prestigio alcanzado en las metrópolis y no, como debiera ser, la respuesta a una "necesidad interna”. Schwarz, escribiendo en 1986, se refiere al carácter imitativo en la recepción de las teorías foráneas: "En los veinte años que llevo dando clases de literatura he asistido al tránsito de la crítica por el impresionismo, la historiografía positivista, el new criticism americano, la estilística, el marxismo, la fenomenología, el estructuralismo, el postestructuralismo y ahora las teorías de la recepción". ${ }^{29}$

Resulta llamativo cuando vemos que este devenir de la crítica no es exclusivo de los países periféricos, sino consustancial a lo que Paul de Man calificó, en 1967, su crisis:

Para ceñirnos por el momento a los síntomas puramente
externos, observamos que el aspecto crítico de la situación
resulta evidente, por ejemplo, en la rapidez con que su-
cesivamente surgen tendencias conflictivas que condenan
al abandono inmediato lo que poco antes podía parecer
vanguardismo a ultranza [...] No es fácil estar al corriente
con los nombres y las tendencias que se suceden con una
rapidez desconcertante. ${ }^{30}$

El escenario de la crítica, por tanto, es más complejo que de lo que supone su comprensión periférica, pues lo que Schwarz desconsidera no es solo que toda crítica efectiva se da como crisis, sino también el hecho de que las reglas y convenciones que la sostenían se han desplomado. No sabemos cuál será hoy el parecer del crítico marxista, pero aquel juicio ha prevalecido en gran parte de la crítica latinoamericana, que ve con preocupación narcisista el hecho de que "su lugar de privilegio epistemológico o discursivo relativo está siendo desplazado por la globalización y la articulación de una nueva hegemonía norteamericana en las Américas" ${ }^{31}$. Quizá ello es lo que le impide comprender que la apuesta por la diferencia no consiste en un ajuste metropolitano desde su margen, ni en una simple inversión de términos, en un movimiento que le permita a la cultura periférica pasar de subalterna a dominante. Tal comentario lleva a pensar que la ironía esconde la ignorancia, pero sabemos que su malestar se da con una filosofía que tiene en 
su base al pensamiento nietzscheano, el que se ha sobrepuesto sobre un marxismo que se mira reduccionista no por sobrevalorar la cuestión de la determinación económica, sino porque desconoce que la clase está atravesada históricamente por la raza, la etnia y el género, cuyo reconocimiento sí se da por una "necesidad" de democracia radical. Como también desconoce que el vínculo entre lo económico y lo cultural no acontece simplemente a través de un carácter postizo, sino mediante un ejercicio de violencia colonial que traspasa al Brasil republicano. En otras palabras, el economicismo de Schwarz no considera que la estructura social esté atravesada por un etnocentrismo jerarquizador y que, por tanto, desplaza las categorías sobre las que se ha edificado la historia latinoamericana. Plantear el asunto como la lucha de la copia por sobreponerse al original es reducir los términos de la discusión e intentar ridiculizar el trabajo que Silviano y otros han desarrollado precisamente para develar aquellas diferencias jerarquizadas, cuestión que se hace con la clara conciencia de que tal crítica habita el mismo espacio que quiere deconstruir. Por ello me gustaría insistir en que el trabajo ensayístico de Silviano Santiago no desconoce la dependencia económica ni cultural de Brasil y América Latina, pero ha decidido suspender los términos conservadores del debate, que se han centrado en cuánto le debe la periferia al centro, en su repetición y semejanza, pues ello es contribuir a su dominación; la estrategia de lectura suplementaria apunta precisamente a develar la fuerza coercitiva sobre la que hay que trabajar, y a pesar de la cual se logra inaugurar una diferencia irreductible que consigue inscribirse en el trazo discursivo etnocéntrico, ya que la captura de la alteridad (allá), como muestra el relato de los caníbales de Jean de Léry, termina alterando el discurso occidental (acá) de su representación: "el otro vuelve al mismo" inquietando su devenir. ${ }^{32}$
32. DE CERTEAU, Michel.

"Etno-grafía. La oralidad o el espacio del otro: Lery", 1999, p. 203-233.

33. SAID, Edward. "Traveling Theory". Raritan, 1982, p. 42.

Una estrategia de lectura así abre miradas sobre la colonización, la dependencia y la cultura que visualizan un campo activo que suspende la noción de imitación, a la vez que contesta sus fuerzas coercitivas. En su reflexión sobre las teorías viajeras, Edward Said señaló que se debe recurrir al préstamo teórico si se busca "eludir las limitaciones de nuestro entorno intelectual inmediato" 33 , y no otra cosa ha venido haciendo Silviano desde los años setenta, gracias a la deconstrucción y la arqueología, herramientas que hasta hoy le han permitido un trabajo activo que devela los reduccionismos del pensamiento 
34. HOISEL, Evelina. "Silviano Santiago e a disseminação do saber", 1997, p. 48.

35. CLIFFORD, James.

"Notes on Travel and Theory". Inscriptions, 1989, p.172.

36. CORONIL, Fernando.

"Transculturation and Politics of Theory: Countering the Center, Cuban Counterpoint", 1995, p. 9-56. moderno etnocéntrico. Así lo señala una de sus alumnas de maestría, cuando comenzaron a releer la historia cultural de Brasil:

del siglo XVI al siglo XX, la literatura brasileña, o mejor, la cultura brasileña, fue revisitada, rescrita en sus diversos periodos, en una perspectiva interdisciplinar, donde el discurso de la literatura, de la historiografía, de la sociología y de la etnología dialogaban dramáticamente, develando a través de diversas marcas textuales, un proceso de réplica y violencia cultural hasta entonces encubierto. Se asistía en aquel momento [en las clases de 1975 y 1976], al inicio de un proceso pedagógico cultural hoy diseminado en varias líneas de investigación en los cursos de postgrado de Literatura del país. ${ }^{34}$

Evelina Hoisel agrega que en aquellos cursos se enseñaba a pensar la relación colonizador/colonizado desde el punto de vista del colonizado, pues hacer lo contrario implicaba caer en la ideología de las fuentes y las influencias. Con ello Silviano no solo se adelantaba a los estudios postcoloniales, sino que practicaba lo que en el lenguaje de hoy se llama discurso del otro, pero sin dejar de lado, como Edward Said en sus inicios, la agencia. Tal mirada permite incluso complejizar el viaje teórico tal como lo describió el autor de Orientalismo, puesto que su comprensión mantiene una idea lineal del desarrollo o viaje intelectual. Para Said, una teoría sigue un derrotero que parte desde un punto de origen, luego atraviesa una distancia, espacial y temporal, para ser posteriormente recibida, con o sin resistencia; por último, ya adaptada, la teoría viajera será transformada en función de nuevos usos. Con este modelo, aparece una alternativa a la idea simplista de original y copia, al acentuar el trabajo transformador "local", pero su linealidad mantiene prácticamente los términos del debate; como señaló uno de sus principales críticos, James Clifford, esas

[...] etapas se leen como una historia demasiado familiar de inmigración y aculturación. Un camino tan lineal no puede hacer justicia a los circuitos de realimentación, a las apropiaciones ambivalentes y a las resistencias que caracterizan los viajes de teorías, y de teóricos, entre lugares del 'primer' y 'tercer' mundo. ${ }^{35}$

En su introducción a la reedición inglesa de Contrapunteo cubano del tabaco y el azúcar (1995), Fernando Coronil señalaba que el viaje teórico es eminentemente transcultural, pero su domesticación lineal se impone cuando se termina canonizando autores. Para Coronil, al atributo imperial axiomatizador se da mediante la instauración de cánones y no a partir de los teóricos y sus teorías ${ }^{36}$. En este sentido, más que de viajes 
de un punto a otro, los ensayos de Silviano nos hablan de una diseminación del saber que no se queda quieto en ningún lugar, que no se deja fijar. Su nomadismo reconoce una dinámica constante de intercambio no solo entre países, sino entre segmentos de un mismo país, un movimiento que apuesta por impugnar las relaciones de poder (económicas, culturales, sociales) que niegan la alteridad de múltiples formas. Ello pasa, a su vez, por una toma de conciencia de las estrategias discursivas empleadas para identificar incluso cuándo el lobo se viste de cordero. Esto dice relación con el anquilosamiento de las ideas colonizadoras y eurocéntricas tal como lo indicamos en el caso de Habermas. En este sentido, ensanchar los espacios de crítica no ha significado para este ensayista el abandono de la estrategia deconstructivista a la que supuestamente habría llegado para colocarse de mode, pues es ella misma la que le ha permitido subrayar un sinfín de suplementos en todos los registros que ha abordado hasta hoy.

El hecho de que Silviano haya retomado la senda abierta por Montaigne como medio de lucha, nos habla de un intelectual comprometido con la democracia, dentro y fuera de la academia. Su trabajo ensayístico constituye un aporte a la teoría latinoamericana, un aporte que todavía no alcanza el reconocimiento merecido fuera de Brasil, donde actualmente se le considera como el crítico más relevante, gracias a que su trabajo no ha perdido sino ganado fuerza con los años. Este desconocimiento habla no solo de una falta de diálogo en el espacio intelectual latinoamericano, sino de un desinterés del mismo por Brasil, reinscribiendo una geopolítica del saber que se dice criticar. Desde "El entre-lugar del discurso latinoamericano”, escrito en plena época del discurso dependentista, que ensalzaba lo local, la ensayística de Silviano ha mostrado una preocupación constante por pensar más allá de Brasil, por no someterse a una geografía construida imperialmente. Es de esperar que las nuevas generaciones latinoamericanas piensen más allá del español. Para tal tarea, el ensayo bien puede ser la mejor opción, dado que su forma permite mirar al mundo entero como una tierra extranjera, mientras las fronteras quedan para las cancillerías. 


\section{Referencias}

ADORNO, Th. W. "El ensayo como forma". In:

Notas sobre literatura. Trad. Alfredo Brotons. Madrid: Akal, 2009 [1954-1958]. p. 11-34.

ASSIS, Machado de. "Notícia da atual literatura: Instinto de nacionalidade".In: Obra Completa, vol. III. Rio de Janeiro: José Aguilar, 1962. p. 801-809.

CLIFFORD, James. "Notes on Travel and Theory". Inscriptions. n. 5, p. 177-188, 1989.

CORONIL, Fernando. "Transculturation and Politics of Theory: Countering the Center, Cuban Counterpoint”. In: ORTIZ, Fernando. Cuban Counterpoint Tobacco and Sugar. Trad. Harriet de Onís. Durham: Duke University Press, 1995, p. 9-56.

CUNHA, Eneida Leal. "Leituras da dependência cultural”. In: SOUZA, Eneida Maria de; MELLO MIRANDA, Wander (orgs.). Navegar é preciso, viver: escritos para Silviano Santiago. Belo Horizonte, Salvador, Niterói: UFMG, Ed. UFBA, Ed. UFF, 1997, p.126-139.

CURTIUS, E. R. "Goethe como crítico". In: . Ensayos críticos acerca de literatura europea. Trad. E. Valentí. Madrid: Visor, 1989 [1950].

DE CERTEAU, Michel. "Etno-grafía. La oralidad o el espacio del otro: Lery". In: . La escritura de la

historia. Trad. Jorge López Moctezuma. México: Universidad Iberoamericana, 1999 [1978]. p. 203-233.

DE MAN, Paul. "Crítica y crisis". In: . Visión y ceguera. Ensayos sobre la retórica de la crítica contemporánea. Trad. Hugo Rodríguez-Vecchini y Jacques Lezra. Puerto Rico: Universidad de Puerto Rico, 1991 [1967]. p. 7-25.

ECKERMANN, J. P. Conversaciones con Goethe. Trad. Rosa Sala Rose. Barcelona: Acantilado, 2005.

GUHA, Ranajit. "Sobre algunos aspectos de la historiografía colonial de la India”. In: RODRÍGUEZ FREIRE, raúl (org.). Estudios Subalternos: Una cartografía a (des)tiempo. Popayán: Universidad del Cauca, 2013 [1982], p. 75-82.

HABERMAS, Jürgen. "La modernidad, un proyecto incompleto”. In: FOSTER, Hal (org.). La posmodernidad. Trad. Jordi Filba. México: Kairós, 1988, p. 19-36. 
HOISEL, Evelina. "Silviano Santiago e a disseminação do saber”. In: SOUZA, Eneida Maria de; MELLO MIRANDA, Wander (orgs.). Navegar é preciso, viver, escritos para Silviano Santiago. Belo Horizonte, Salvador, Niterói: UFMG, Ed. UFBA, Ed. UFF, 1997, p. 41-49.

LÉVI-STRAUSS, Claude. Tristes trópicos. Trad. de Noelia Bastard. Buenos Aires: Paidós, 1988 [1955].

LÓPEZ, Natalia y RODRÍGUEZ FREIRE, raúl. "Sobre Estudios Culturales, literatura y subalternidad: entrevista a John Beverley”. Revista de Crítica Cultural. n. 36, p. 64-69, 2007.

RICHARD, Nelly. La estratificación de los márgenes. Santiago: Francisco Zegers, 1989.

1989.

. Masculino/Femenino. Santiago: Francisco Zegers,

. "Periferias culturales y descentramiento de los

márgenes”. Punto de Vista. n. 40, p. 5-7, 1991.

SAID, Edward. "Traveling Theory”. Raritan. n. 1.3, p. 41-67, 1982.

SANTIAGO, Silviano (org.). “Análise e interpretação”. In: . Uma literatura nos trópicos. São Paulo: Perspectiva, 1978, p. 191-207.

. "A pesar de dependiente, universal”. In:

Una literatura en los trópicos. Ensayos de Silviano Santiago. Santiago: Universidad de Chile, 2012 [1982]. p. 97-110.

. "El cosmopolitismo del pobre". In: . Una

literatura en los trópicos: Ensayos de Silviano Santiago. Santiago: Universidad de Chile, 2012 [2002]. p. 213-234.

. "El entre-lugar del discurso latinoamericano". In:

. Una literatura en los trópicos. Ensayos de Silviano

Santiago. Trad. Mary Luz Estupiñán y raúl rodríguez freire. Concepción: Escaparate, 2012 [1971]. p. 57-76.

"El homosexual astuto". In: Una literatura

en los trópicos: Ensayos de Silviano Santiago. Santiago:

Universidad de Chile, 2012 [1999]. p. 99-211.

. Glossário de Derrida. Rio de Janeiro: Francisco

Alves, 1976.

. "Oswald de Andrade. Elogio da tolerância racial".

In: . Ora (direis) puxar conversa! Ensaios literários.

Belo Horizonte: UFMG, 2006. p. 133-145. 
1985.

. "Vale cuanto pesa (la ficción modernista brasileña)". In:__. Una literatura en los trópicos. Ensayos de

Silviano Santiago, Santiago: Universidad de Chile, 2012 [1978]. p. 77-95.

SCHWARZ, Roberto. "Cultura y política en el Brasil (196769). Algunos esquemas”. Casa de las Américas. n. 61, p. 9-32, 1970.

. "Nacional por Subtração". In: Que Horas

São? São Paulo: Companhia das Letras, 2006 [1987]. p. 29-48.

SOVIK, Liv. “'O Haiti é aqui / O Haiti não é aquî': Música popular, dependência cultural e identidade brasileira na polêmica Schwarz-Silviano Santiago”. In: MATO, Daniel (coord.). Estudios y otras prácticas intelectuales latinoamericanas en Cultura y Poder. Caracas: CLACSO/ CEAP, FACES, Universidad Central de Venezuela, 2002, p. 277-286. 